\title{
Accelerated ice-sheet mass loss in Antarctica from 18-year satellite laser ranging measurements
}

\author{
Shuanggen Jin ${ }^{1,2,{ }^{\star}}$, Mosta Abd-Elbaky ${ }^{1,3}$, Guping Feng ${ }^{1}$ \\ ${ }^{1}$ Shanghai Astronomical Observatory, Chinese Academy of Sciences, Shanghai, China \\ ${ }^{2}$ Bulent Ecevit University, Department of Geomatics Engineering, Zonguldak, Turkey \\ ${ }^{3}$ University of Chinese Academy of Sciences, Beijing, China
}

\section{Article history}

Received April 21, 2015; accepted January 8, 2016.

Subject classification:

Gravity variations, Ice mass balance, Antarctica, SLR, GRACE.

\begin{abstract}
Accurate estimation of the ice-sheet mass balance in Antarctic is very difficult due to complex ice sheet condition and sparse in-situ measurements. In this paper, the low-degree gravity field coefficients of up to degree and order 5 derived from Satellite Laser Ranging (SLR) measurements are the first used to determine the ice mass variations in Antarctica for the period 1993-2011, which are compared to Gravity Recovery and Climate Experiment (GRACE). Results show that the ice mass is is decreasing at the rate of $-36 \pm 13 \mathrm{Gt} / \mathrm{y}$ in Antarctica, $-42 \pm 11 \mathrm{Gt} / \mathrm{y}$ in West Antarctica and increasing at $6 \pm 10 \mathrm{Gt} / \mathrm{y}$ in East Antarctica from 1993 to 2011. The ice mass variations from the SLR $5 \times 5$ have a good agreement with the GRACE $5 \times 5$, GRACE $5 \times 5(1 \mho 2)$ and GRACE $(60 \times 60)$ for the entire continent since 2003, but SLR solution of $5 \times 5$ is not sufficient to quantify ice losses in West and East Antarctica, respectively. The rate of ice loss in Antarctica is $-28 \pm 17 \mathrm{Gt} / \mathrm{y}$ for 1993-2002 and $-55 \pm 17 \mathrm{Gt} / \mathrm{y}$ for 2003-2011 within one sigma, indicating significant accelerated ice mass losses since 2003. Furthermore, the results from SLR are comparable with GRACE measurements.
\end{abstract}

\section{Introduction}

The Antarctic ice sheet is the largest ice sheet on Earth, which contains 26.5 million $\mathrm{km}^{3}$ of ice [Steig et al. 2009]. Accurate estimates of its mass variability would greatly contribute to understand global climate change and sea-level change. However, measuring and monitoring Antarctic mass variability is difficult because of the ice sheet's size, thickness and complexity as well as sparse in-situ measurements. Larger differences in estimating the glacier mass balance were found with different time spanning observations [Shepherd and Wingham 2007]. Recent geodetic techniques provided mass balance estimates, such as satellite radar altimetry, interferometric synthetic aperture radar (InSAR) and recent Gravity Recovery and Climate Experiment (GRACE) [Wahr et al. 1998, Tapley et al. 2004, Jin et al. 2011, Shepherd et al. 2012, Jin et al. 2014]. The satellite laser altimetry showed mass gain in East Antarctica at 45 $\pm 7 \mathrm{Gt} / \mathrm{yr}$ in 1992-2003 [Davis et al. 2005], $-31 \pm 12 \mathrm{Gt} / \mathrm{yr}$ in 1992-2002 [Zwally et al. 2005], $+27 \pm 29 \mathrm{Gt} / \mathrm{yr}$ in 1992-2003 [Wingham et al. 2006] and about [-84,-103] Gt/yr in 2003-2007 from Ice, Clouds, and Land Elevation Satellite (ICESat) [Gunter et al. 2009]. Satellite observations showed large ice loss from -48 to $-132 \mathrm{Gt} / \mathrm{yr}$ in West Antarctica and from -4 to $+22 \mathrm{Gt} / \mathrm{yr}$ in East Antarctica within one sigma [Thomas et al. 2004, Shepherd et al. 2012].

The significant loss of ice mass in Antarctica was observed from GRACE measurements [Ramillien et al. 2006, Velicogna and Wahr 2006, Chen et al. 2009, Wu et al. 2010, Barletta et al. 2012, King et al. 2012]. However, larger differences of ice-mass change in Antarctica are found due to some uncertainties and errors, such as technique-specific systematic errors, different Glacial isostatic adjustment (GIA)models, smoothing and filtering effects and leakage errors [Velicogna and Wahr 2013]. In particular, the GIA has been recognized as the major difference in quantifying the mass change in Antarctica from GRACE [Velicogna and Wahr 2006, Barletta et al. 2008]. Furthermore, the observation time span is relatively short.

Satellite Laser Ranging (SLR) technique measures the round trip time of flight of ultrashort pulses of light to determine the distance from ground-based stations to satellites equipped with retroreflectors. Currently the SLR provides millimeter level precision to determine satellite's orbits, which are influenced by temporal variations in the Earth's gravity field. Therefore, SLR can accurately determine the temporal variations of the Earth's low-degree gravity field [Cheng et al. 2013], which can be used to estimate the large-scale temporal 
mass variations, including ice volume change.

In this paper, the ice-sheet mass variations in Antarctica with monthly resolution are the first derived from approximate 18 years of monthly low-degree Stokes coefficients of the Earth's gravity field with degree and order of up to 5 based on SLR measurements (January 1993 May 2011). The new GIA model (W12a) is used from Whitehouse et al. [2012b]. In order to evaluate our results, we compare with ice-sheet mass variations in Antarctica from GRACE observations since 2003. Section 2 shows the observation data and methods. Section 3 presents the results of ice-sheet mass variations in Antarctica and comparison with GRACE observations. Conclusions are given in Section 4.

\section{Observation data and methods}

The weekly low-degree Stokes coefficients of the Earth's gravity field with up to degree and order 5 are determined from SLR measurements with the same strategies as GRACE solution by Cheng et al. [2011]. These products are derived from five geodetic satellites measurements (LAGEOS 1 and 2, Starlette, Ajisai, and Stella). The coefficients are given as variations relative to the mean gravity field GGM02C. The SLR-derived weekly gravity field coefficients are used to estimate the mass lose in Antarctica. The effects of land-ocean leakage are corrected using the forward modelling technique [e.g., Jin and Zou 2015]. In order to evaluate our results, we compare with results from the monthly GRACE data (CSR Level-2 RL05) with harmonic degree and order of up to 5 from January 2003 to May 2011. The degree 1 gravity field coefficients $\left(\mathrm{C}_{10}, \mathrm{C}_{11}\right.$ and $\left.\mathrm{S}_{11}\right)$ are used from Swenson et al. [2008]. On one hand, the degree 2 gravity field coefficients are not replaced by SLR in order to keep the data independent between GRACE and SLR (GRACE $5 \times 5)$. On the other hand, the degree 2 gravity field coefficients are replaced by SLR [Cheng and Tapley 2004] as GRACE $5 \times 5$ (1\&2). In addition, the $300 \mathrm{~km}$ width of Gaussian filter and a special de-striping filter are used [Swenson and Wahr 2006]. In order to compare with SLR solutions, the monthly GRACE data set with harmonic degree and order of up to 60 is also used to obtain the ice-sheet mass variations in Antarctica (GRACE 60×60).

The ice-sheet mass variations in Antarctica in water equivalent thickness can be directly determined by gravity coefficient anomalies $\left(\Delta \mathrm{C}_{\mathrm{lm}}, \Delta \mathrm{S}_{\mathrm{lm}}\right)$ of SLR and GRACE observations as [Jin and Feng 2013, Hassan and Jin 2014]:

$$
\begin{aligned}
& \Delta \mathrm{\eta}_{\text {land }}(\theta, \phi, \mathrm{t})= \\
& =\frac{\mathrm{a} \rho_{\text {ave }}}{3 \rho_{\mathrm{w}}} \sum_{\mathrm{l}=0}^{\infty} \sum_{\mathrm{m}=0}^{\mathrm{l}} \widetilde{\mathrm{P}_{\mathrm{lm}}}(\cos \theta) \frac{2 \mathrm{l}+1}{1+\mathrm{k}_{\mathrm{l}}}\left(\Delta \mathrm{C}_{\mathrm{lm}} \cos (\mathrm{m} \phi)+\right. \\
& \left.+\Delta \mathrm{S}_{\mathrm{lm}} \sin (\mathrm{m} \phi)\right)
\end{aligned}
$$

where $\rho_{\text {ave }}$ is the average density of the Earth, $\rho_{\mathrm{w}}$ is the density of fresh water, a is the equatorial radius of the Earth, $\widetilde{\mathrm{P}_{\mathrm{lm}}}$ is the fully-normalized Associated Legendre Polynomials of degree $l$ and order $\mathrm{m}, k_{l}$ is load-deformation coefficient of degree $l$ [Han and Wahr 1995], $\theta$ is the co-latitude, and $\phi$ is the longitude.

In order to estimate the accurate secular variations of ice-mass change, the GIA influence should be removed. The GIA models describe the ongoing viscoelastic response of the solid Earth to past changes in surface loading by ice and water. Here, we use the recent GIA model W12a for Antarctica, which was driven by a glaciologically-consistent Antarctic deglacial history and constrained to fit observations of past ice extent [Whitehouse et al. 2012a, 2012b]. Therefore, the monthly ice-sheets mass changes in Antarctica can be obtained from SLR (1993.01-2011.05, about 18 years) and GRACE (2003.01-2011.05, about 8 years).

\section{Results and discussions}

Since the ice-sheet mass variation time series have strong seasonal signals, seasonal signals are removed from the SLR and GRACE time series of the ice mass variations at each grid point. The secular and quadratic signals of ice mass variations are estimated in Antarctica after removing the seasonal signals.

\subsection{Secular variations of ice-sheets}

The trends of ice-sheet mass variations in Antarctica from January 2003 to May 2011 are estimated from

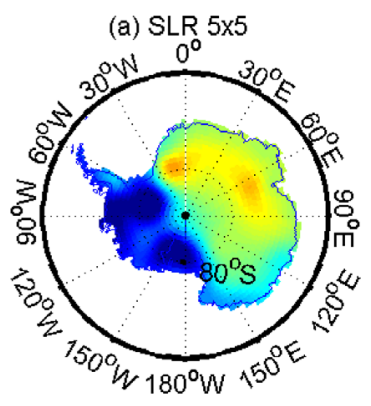

(c) GRACE $5 \times 5$

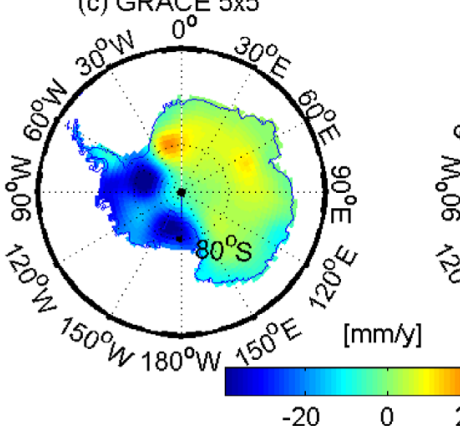

$-20$

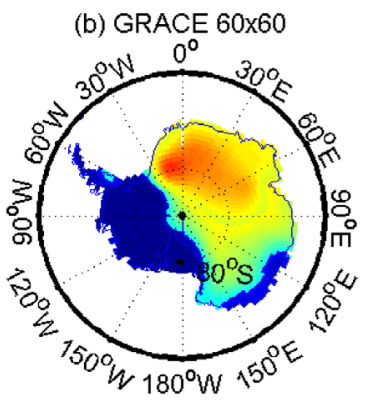

(d) GRACE $5 \times 5(182)$

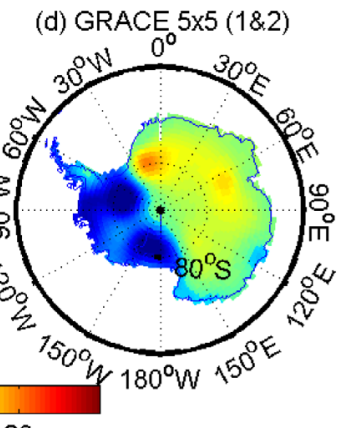

Figure 1. The trends of ice-sheet mass variations over Antarctica from (a) SLR 5×5, (b) GRACE $60 \times 60$, (c) GRACE 5×5, and (d) GRACE $5 \times 5(182)$ with replacement of degree 1 and $C_{20}$. Unit is $\mathrm{mm} / \mathrm{y}$ of equivalent water thickness change. The GIA effect is removed. 


\begin{tabular}{cccc}
\hline Models & & January 2003 - May 2011 & \\
\cline { 2 - 4 } & West Antarctica $(\mathrm{Gt} / \mathrm{y})$ & East Antarctica $(\mathrm{Gt} / \mathrm{y})$ & Antarctica $(\mathrm{Gt} / \mathrm{y})$ \\
\hline SLR $5 \times 5$ & $-66 \pm 13$ & $12 \pm 15$ & $-55 \pm 17$ \\
GRACE $60 \times 60$ & $-105 \pm 12$ & $60 \pm 15$ & $-45 \pm 18$ \\
GRACE $5 \times 5$ & $-51 \pm 18$ & $16 \pm 13$ & $-36 \pm 19$ \\
GRACE $5 \times 5(182)$ & $-61 \pm 15$ & $30 \pm 16$ & $-36 \pm 13 \mathrm{Gt} / \mathrm{y}$ \\
\hline
\end{tabular}

Table 1. The trends of ice mass variations in Antarctica based on four gravity models.

SLR and GRACE solutions. Figure 1 shows the linear term of ice-sheet mass variations over Antarctica from (a) SLR 5×5, (b) GRACE $60 \times 60$, (c) GRACE 5×5, and (d) GRACE $5 \times 5$ (1\&2) with replacement of degree 1 and $\mathrm{C}_{20}$. Unit is millimeter of equivalent water thickness change per year, $\mathrm{mm} / \mathrm{y}$. The GIA effect is removed. The linear trend of ice-sheet mass variations from SLR almost agrees with the GRACE results, indicating that the low-degree gravitational coefficients obtained by SLR are sensitive and efficient to correctly capture the ice mass change in Antarctica. The ice mass is significantly losing in West Antarctica and gaining in East Antarctica, which almost agree each other. The linear trend of ice sheets variations in Antarctica is $-55 \pm 17$ $\mathrm{Gt} / \mathrm{y}$ based on SLR $5 \times 5,-45 \pm 18 \mathrm{Gt} / \mathrm{y}$ based on GRACE $60 \times 60,-36 \pm 19 \mathrm{Gt} / \mathrm{y}$ based on GRACE $5 \times 5$, and $-31 \pm 17$ $\mathrm{Gt} / \mathrm{y}$ based on GRACE $5 \times 5$ (1\&2). For West Antarctica, the linear trend is $-66 \pm 13 \mathrm{Gt} / \mathrm{y}$ based on SLR $5 \times 5$, $-105 \pm 12 \mathrm{Gt} / \mathrm{y}$ based on GRACE $60 \times 60,-51 \pm 18 \mathrm{Gt} / \mathrm{y}$ based on GRACE $5 \times 5$, and $-61 \pm 15 \mathrm{Gt} / \mathrm{y}$ based on GRACE $5 \times 5$ (1\&2) within one sigma. For East Antarctica, the linear trend is $11.58 \pm 15.05 \mathrm{Gt} / \mathrm{y}$ based on SLR $5 \times 5,60 \pm 15 \mathrm{Gt} / \mathrm{y}$ based on GRACE $60 \times 60,16 \pm 13 \mathrm{Gt} / \mathrm{y}$

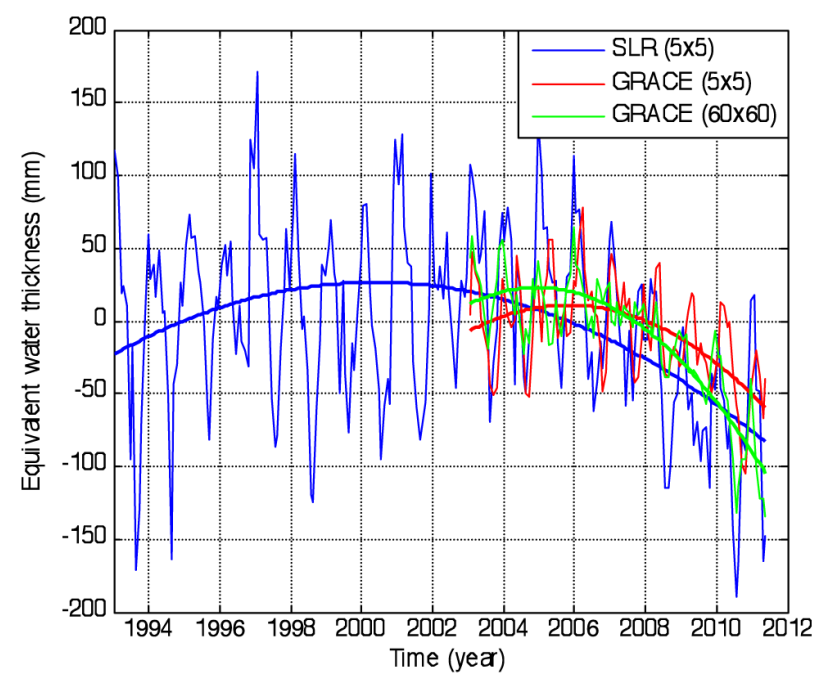

Figure 2. Time series of ice-sheets mass variations in $\left(74.5^{\circ} \mathrm{S}\right.$, $\left.144.5^{\circ} \mathrm{W}\right)$ from SLR $5 \times 5$, GRACE $5 \times 5$ and GRACE $60 \times 60$. based on GRACE $5 \times 5$, and $30 \pm 16 \mathrm{Gt} / \mathrm{y}$ based on GRACE $5 \times 5(1 \& 2)$ (Table 1). It indicates that the mass losses from SLR in West Antarctica are the dominant contributor to ice mass loss from Antarctica. The values with GRACE $60 \times 60$ are twice bigger than GRACE $5 \times 5$. In contrast, there seems to be a better agreement for the entire continent. When we process GRACE data using $300 \mathrm{~km}$ width of Gaussian filter, the noise is attenuated, but the geophysical signal too. It may apply a restoration factor to GRACE data after filtering [Landerer and Swenson 2012].

In addition, we also estimate the ice-sheet mass variations over Antarctica from January 1993 to May 2011 based on SLR $5 \times 5$. The ice-sheet mass is significantly losing at $-36 \pm 13 \mathrm{Gt} / \mathrm{y}$ in Antarctica, $-42 \pm 11$ $\mathrm{Gt} / \mathrm{y}$ in West Antarctica, and $6 \pm 10 \mathrm{Gt} / \mathrm{y}$ in East Antarctica, which are close to the combined results by Shepherd et al. [2012].

\subsection{Accelerated variations of ice-sheets}

The time series of ice mass-loss from both SLR and GRACE clearly shows a accelerating variation in ice mass. For example, Figure 2 shows the time series of ice mass variations from $1993-2011$ at $\left(74.5^{\circ} \mathrm{S}, 144.5^{\circ} \mathrm{W}\right)$. A quadratic trend is estimated from the monthly time series of ice-sheet mass variations in Antarctica. Figure 3 shows the quadratic term of ice-sheet mass variations over Antarctica from (a) SLR 5×5, (b) GRACE 60×60, (c) GRACE $5 \times 5$, and (d) GRACE $5 \times 5(1 \& 2)$. The acceleration in ice sheet mass loss for the observed period is $-18 \pm 9 \mathrm{Gt} / \mathrm{y}^{2}$ based on SLR $5 \times 5,-5.8 \pm 9 \mathrm{Gt} / \mathrm{y}^{2}$ based on GRACE $60 \times 60,-15 \pm 7 \mathrm{Gt} / \mathrm{y}^{2}$ based on GRACE $5 \times 5$, and $-5.8 \pm 8 \mathrm{Gt} / \mathrm{y}^{2}$ based on GRACE $5 \times 5$ (1\&2). These are consistent with GRACE and satellite altimetry observations, e.g., the ice depletion of $-4.4 \pm 16 \mathrm{Gt} / \mathrm{y}^{2}$ from GRACE by King et al. [2012], while Velicogna [2009] showed larger ice-loss acceleration of $-26 \pm 14 \mathrm{Gt} / \mathrm{y}^{2}$ based on GRACE data over the period 2002 to 2009. Furthermore, the quadratic term of the ice-sheet mass variations over Antarctica is estimated from January 1993 to May 2011 based on SLR $5 \times 5$. The acceleration of ice sheets variations in Antarctica is $-2.6 \pm 5 \mathrm{Gt} / \mathrm{y}^{2}$, 
(a) SLR $5 \times 5$

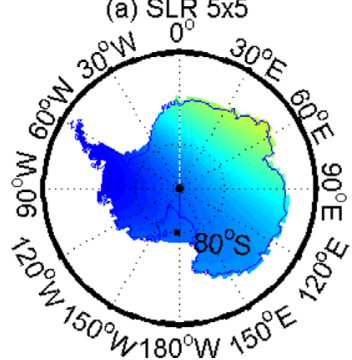

(c) GRACE $5 \times 5$

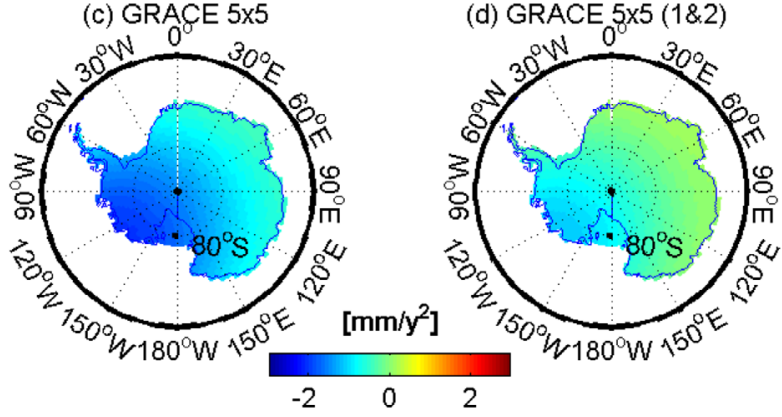

Figure 3. The quadratic term of ice-sheet mass variations over Antarctica from (a) SLR 5×5, (b) GRACE 60×60, (c) GRACE 5×5, and (d) GRACE $5 \times 5$ (1\&2).

which is smaller than Rignot et al. [2011]'s solution of $-14.5 \pm 2 \mathrm{Gt} / \mathrm{y}^{2}$.

\subsection{Interannual variations}

The ice mass-loss from both SLR and GRACE clearly has a significant interannual variation in Antarc- tica. In order to analyze the interannual variability of the ice sheets in Antarctica, the trends of ice mass variations are obtained every 3-year (in $\mathrm{mm}$ of equivalent water thickness change) in Antarctica from January 1993 to January 2011 based on SLR $5 \times 5$ (Figure 4). Here the 3 -year rate is estimated for matching same time spanning for 1993-2011(SLR) and 2003-2011 (GRACE). Significant melting of ice mass in West Antarctica was starting since 2005 and before it has almost less ice mass loses. We furthermore compare with GRACE solutions from January 2003 to January 2011 (Figure 5). Excluding the different trends with short observations of two years from GRACE, the other two trends for 2005-2008 and 2008-2011 are similar, which confirm significant decrease in East Antarctica since 2005 from GRACE. Even though the rate of ice mass change from SLR $5 \times 5$ is smaller than those from GRACE $60 \times 60$, the spatial pattern and trend agree with each other.

We also compare with the in-situ Global Positioning System (GPS) observations, which measures vertical crustal displacement that reflects ice mass loading variations. Figure 6 shows the time series of vertical displacement estimated from SLR $5 \times 5$, GPS, GRACE $60 \times 60$ and GRACE $5 \times 5$ at SYOG station $\left(69.5^{\circ} \mathrm{S}\right.$, $39.5^{\circ} \mathrm{E}$ ) from 2003 to 2011 . They show quite similar secular trend, especially GPS, SLR $5 \times 5$ and GRACE $5 \times 5$. The linear trend is $-0.37 \mathrm{~mm} / \mathrm{y}$ from SLR $5 \times 5$, (a) 1993-1995

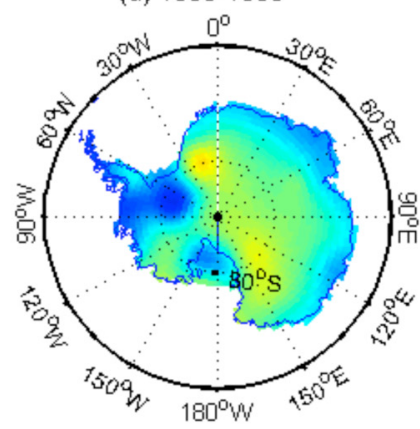

(d) 2002-2004

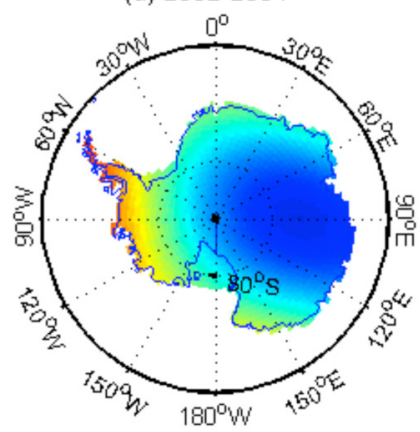

(b) 1996-1998

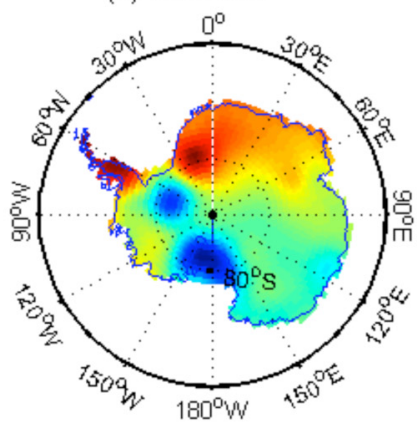

(e) $2005-2007$

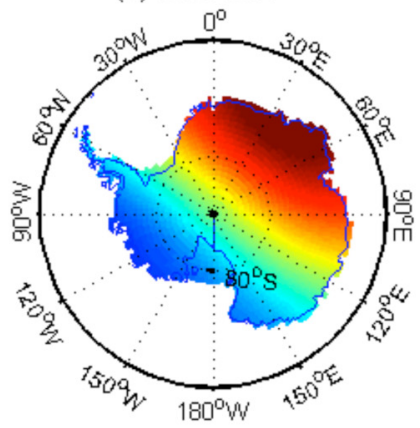

(c) $1999-2001$

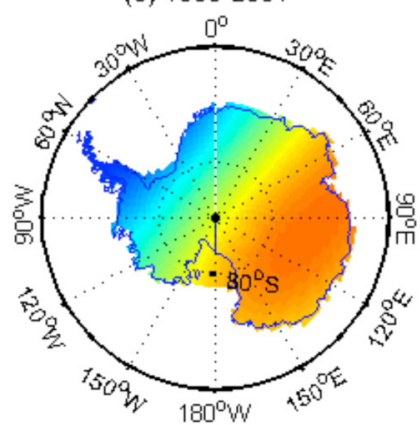

(f) 2008-2010

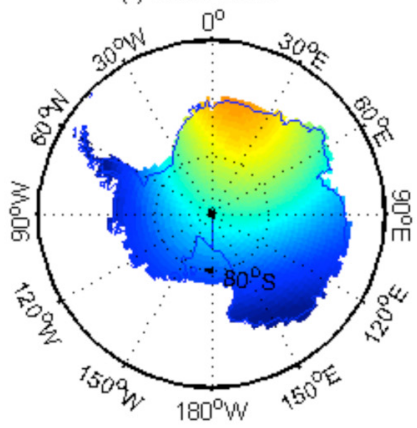

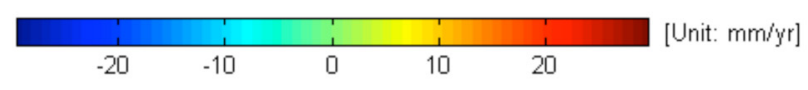

Figure 4. The trends of ice mass variations every 3-year (in mm of equivalent water thickness change) in Antarctica from January 1993 to December 2010 based on SLR $5 \times 5$. 
(a) 2003-2004

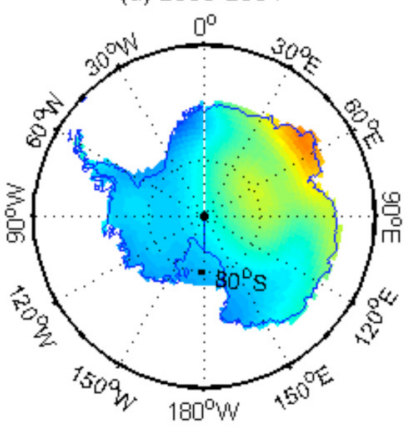

(b) 2005-2007

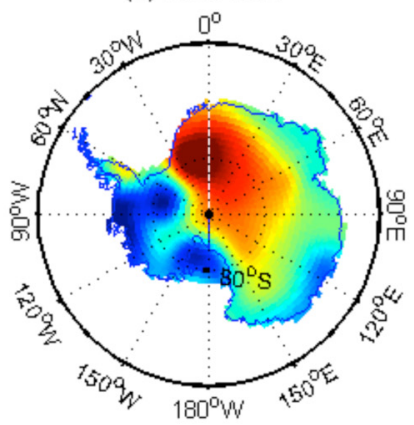

(c) $2008-2010$

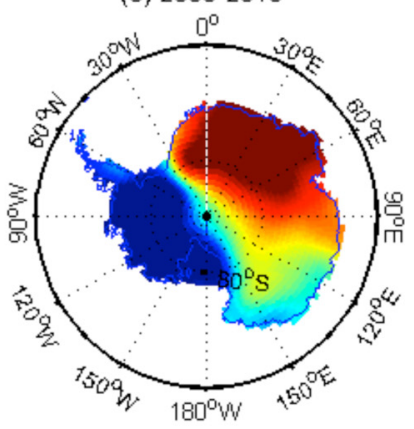

$-20$

20

[Unit: $\mathrm{mm} / \mathrm{yr}$ ]

Figure 5. The trends of ice mass variations every 3-year (in mm of equivalent water thickness change) in Antarctica from January 2003 to December 2010 based on GRACE $60 \times 60$.

$-0.16 \mathrm{~mm} / \mathrm{y}$ from GPS, $-0.29 \mathrm{~mm} / \mathrm{y}$ from GRACE $5 \times 5$ and $-0.77 \mathrm{~mm} / \mathrm{y}$ from GRACE $60 \times 60$. The difference between SLR $5 \times 5$ and GRACE $5 \times 5$ is only $-0.08 \mathrm{~mm} / \mathrm{y}$. The difference between SLR $5 \times 5$ and GPS is -0.21 $\mathrm{mm} / \mathrm{y}$, mainly because the GPS observations just reflect deformation only in the specific locations, while the SLR $5 \times 5$ results reflect the mass variations averaged over a large spatial scale. The GRACE $60 \times 60$ result is larger than the other three results, mainly due to the influence of higher spherical harmonics coefficients.

In addition, we evaluate the ice-sheet mass variations over Antarctica from January 1993 to May 2011 based on SLR $5 \times 5$. Figure 7 shows the linear and quadratic term of ice-sheet mass variations over Antarctica from 1993 to 2011 based on SLR $5 \times 5$. The GIA effect is removed. In recent 19 years, the ice-sheet mass is substantially losing in West Antarctica, the ice-sheet is slowly gaining in East Antarctica. The linear trend of ice sheets variations is $-36.43 \pm 13.41 \mathrm{Gt} / \mathrm{y}$ in Antarctica, $-42.11 \pm 11.42$ $\mathrm{Gt} / \mathrm{y}$ in West Antarctica, and 5.68 $\pm 10.19 \mathrm{Gt} / \mathrm{y}$ in East Antarctica with one sigma. The quadratic term of ice

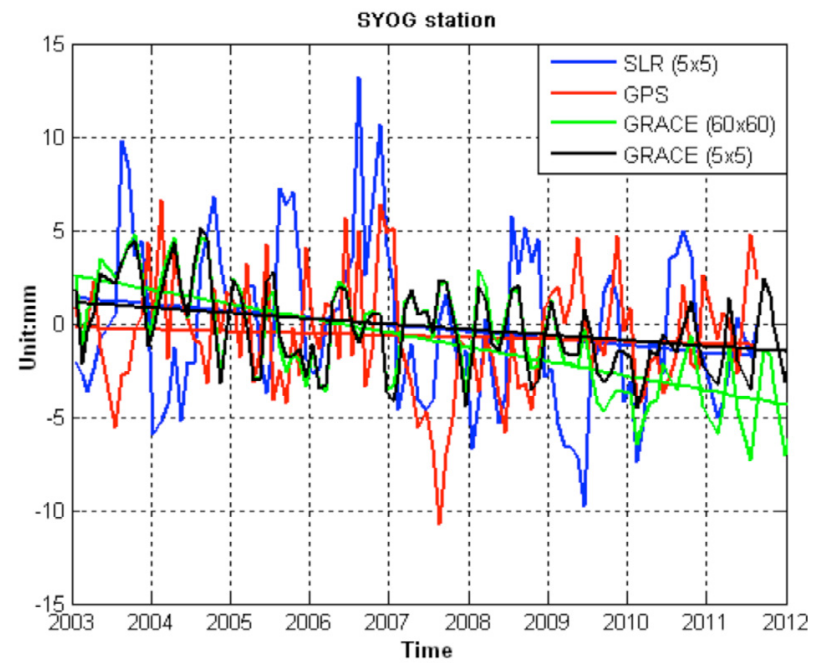

Figure 6. Time series of vertical displacement estimated from SLR $5 \times 5$ (green), GPS (red), GRACE $60 \times 60$ (blue) and GRACE $5 \times 5$ (black) at SYOG station $\left(69.5^{\circ} \mathrm{S}, 39.5^{\circ} \mathrm{E}\right)$.
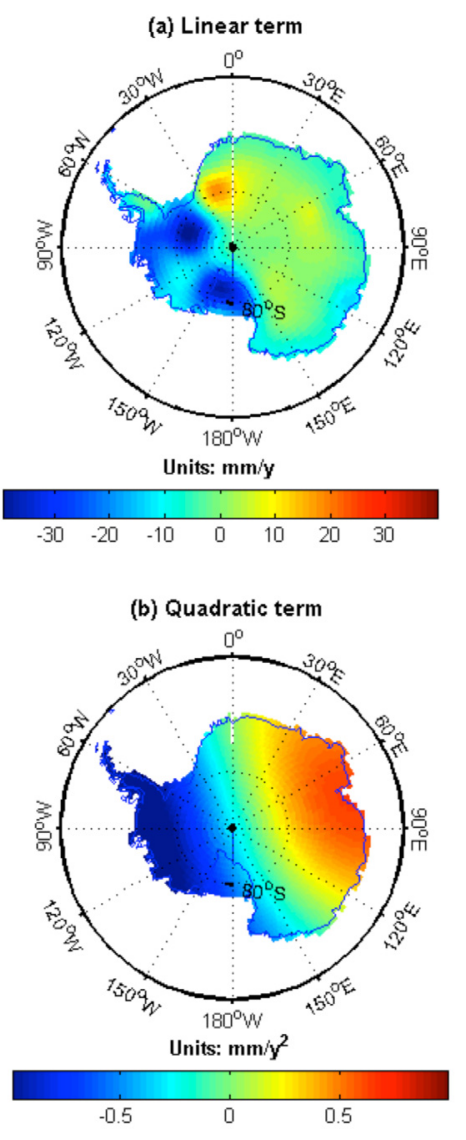

Figure 7. The linear and quadratic term of ice-sheet mass variations over Antarctica from 1993 to 2011 based on SLR $5 \times 5$.

sheets variations is $-2.63 \pm 4.78 \mathrm{Gt} / \mathrm{y} 2$ in Antarctica, $-3.75 \pm 4.17 \mathrm{Gt} / \mathrm{y}^{2}$ in West Antarctica and $1.70 \pm 3.07$ $\mathrm{Gt} / \mathrm{y}^{2}$ in East Antarctica with one sigma.

\section{Conclusions}

In this paper, the monthly ice-sheets mass variations in Antarctica are the first obtained and investigated from low-degree time-variable gravity field of up to degree and order 5 based on SLR data from 1993 to 2011. The trend of ice mass variations is $-36 \pm 13 \mathrm{Gt} / \mathrm{y}$ in Antarctica, $-42 \pm 11 \mathrm{Gt} / \mathrm{y}$ in West Antarctica and 
5.7 $\pm 10 \mathrm{Gt} / \mathrm{y}$ in East Antarctica from 1993 to 2011. The ice mass variations from the SLR $5 \times 5$ have a good agreement with the GRACE $5 \times 5$, GRACE $5 \times 5(1 \& 2)$ and GRACE $(60 \times 60)$ for the entire continent.since 2003 , but SLR solution of $5 \times 5$ is not sufficient to quantify ice losses in West and East Antarctica, respectively. In addition, significant accelerated ice-sheet mass losses are found since 2003 with the rate of $-28 \pm 17 \mathrm{Gt} / \mathrm{y}$ for 1993-2002 and -55 $\pm 17 \mathrm{Gt} / \mathrm{y}$ for 2003-2011. The acceleration of ice sheets variations is $-2.6 \pm 5 \mathrm{Gt} / \mathrm{y}^{2}$ from 1993 to 2011 and $-7.5 \pm 9 \mathrm{Gt} / \mathrm{y}^{2}$ from 2003 to 2011 in Antarctica. Therefore, ice mass in Antarctica has less loses during 1993-2002 and fast loses from 2003-2011, particularly since 2005. These results indicate that SLR observations can provide insights into Antarctic ice mass variations from 1993 to 2011 and allow us to monitor the monthly Antarctic ice mass variations prior to the launch of GRACE mission in 2002. In addition, some gaps after GRACE may be expected to be made up for with more SLR satellites observations in the near future.

Acknowledgements. We gratefully thank the Center for Space Research of University of Texas at Austin for providing gravity field coefficients from GRACE and SLR. This research is supported by the Main Direction Project of Chinese Academy of Sciences (Grant No. KJCX2-EW-T03), Shanghai Science and Technology Commission Project (Grant No. 12DZ2273300) and National Natural Science Foundation of China (NSFC) Project (Grant No. 11173050 and 11373059).

\section{References}

Barletta, V.R., R. Sabadini and A. Bordoni (2008). Isolating the PGR signal in the GRACE data: impact on mass balance estimates in Antarctica and Greenland, Geophys. J. Int., 172, 18-30.

Barletta, V.R., L.S. Sørensen and R. Forsberg (2012). Variability of mass changes at basin scale for Greenland and Antarctica, Cryosphere Discuss., 6, 33973446.

Chen, J.L., C.R. Wilson, D. Blankenship and B.D. Tapley (2009). Accelerated Antarctic ice loss from satellite gravity measurements, Nature Geosci, 2, 859-862.

Cheng, M., and B.D. Tapley (2004). Variations in the Earth's oblateness during the past 28 years, J. Geophys. Res., 109, B09402.

Cheng, M., J.C. Ries and B.D. Tapley (2011). Variations of the Earth's Figure Axis from Satellite Laser Ranging and GRACE, J. Geophys. Res., 116, B0140 9.

Cheng, M.K., B.D. Tapley and J.C. Ries (2013). Deceleration in the Earth's oblateness, J. Geophys. Res. Solid Earth, 118, 1-8.

Davis, C.H., Y. Li, J.R. McConnell, M.M. Frey and E. Hanna (2005). Snowfall-driven growth in East Antarctic ice sheet mitigates recent sea-level rise, Science, 308, 1898-1901.
Gunter, B., T. Urban, R. Riva, M. Helsen, R. Harpold, S. Poole, P. Nagel, B. Schutz and B. Tapley (2009). A comparison of coincident GRACE and ICESat data over Antarctica, J. Geodesy, 83, 1051-1060.

Han, D., and J. Wahr (1995). The viscoelastic relaxation of a realistically stratified earth, and a further analysis of post-glacial rebound, Geophys. J. Int., 120, 287-311.

Hassan, A.A., and S.G. Jin (2014). Lake level change and total water discharge in the East Africa Rift Valley from satellite-based observations, Global Planet. Change, 117, 79-90; doi:10.1016/j.gloplacha.2014. 03.005.

Jin, S.G., L.J. Zhang and B.D. Tapley (2011). The understanding of length-of-day variations from satellite gravity and laser ranging measurements, Geophys. J. Int., 184 (2), 651-660; doi:10.1111/j.1365-246X.2010. 04869.x.

Jin, S.G., and G.P. Feng (2013). Large-scale variations of global groundwater from satellite gravimetry and hydrological models, 2002-2012, Global Planet. Change, 106, 20-30; doi:10.1016/j.gloplacha.2013.02.008.

Jin, S.G., G.P. Feng and O. Anderson (2014). Errors of mean dynamic topography and geostrophic currents estimates in China's Marginal Sea from GOCE and satellite altimetry, J. Atmos. Ocean. Tech.; doi:10.11 75/JTECH-D-13-00243.1.

Jin, S.G., and F. Zou (2015). Re-estimation of glacier mass loss in Greenland from GRACE with correction of land-ocean leakage effects, Global Planet. Change, 135, 170-178; doi:10.1016/j.gloplacha.2015.11.002.

King, M.A., R.J. Bingham, R. Moore, P.L. Whitehouse, M.J. Bentley and G.A. Milne (2012). Lower satellitegravimetry estimates of Antarctic sea-level contribution, Nature, 491, 586-589.

Landerer, F.W., and S.C. Swenson (2012). Accuracy of scaled GRACE terrestrial water storage estimates, Water Resour. Res., 48, W04531, 11 p.; doi:10.1029/ 2011WR011453.

Ramillien, G., A. Lombard, A. Cazenave E.R. Ivins, M. Llubes, F. Remy and R. Biancale (2006). Interannual variations of the mass balance of the Antarctica and Greenland ice sheets from GRACE, Global Planet. Change, 53, 198-208.

Rignot, E., I. Velicogna, M.R. van den Broeke, A. Monaghan and J.T.M. Lenaerts (2011). Acceleration of the contribution of the Greenland and Antarctic ice sheets to sea level rise, Geophys. Res. Lett., 38, L05503.

Shepherd, A., and D. Wingham (2007). Recent sea-level contributions of the Antarctic and Greenland ice sheets, Science, 315, 1529-1532.

Shepherd, A., E.R. Ivins, A. Geruo et al. (2012). A rec- 
onciled estimate of ice-sheet mass balance, Science, 338 (6111), 1183-1189; doi:10.1126/science.1228102.

Steig, E.J., D.P. Schneider, S.D. Rutherford, M.E. Mann, J.C. Comiso and D.T. Shindell (2009). Warming of the Antarctic ice-sheet surface since the 1957 International Geophysical Year, Nature, 457 (7228), 459-462.

Swenson, S., and J. Wahr (2006), Post-processing removal of correlated errors in GRACE data, Geophys. Res. Lett., 33, L08402; doi:10.1029/2005GL025285.

Swenson, S., D. Chambers and J. Wahr (2008). Estimating geocenter variations from a combination of GRACE and ocean model output, J. Geophys. Res., 113, B08410.

Tapley, B.D., S. Bettadpur, M.M. Watkins and C. Reigber (2004). The gravity recovery and climate experiment; Mission overview and early results, Geophys. Res. Lett., 31, L09607.

Thomas, R., E. Rignot, G. Casassa, P. Kanagaratnam, C. Acuña, T. Akins, H. Brecher, E. Frederick, P. Gogineni, W. Krabill, S. Manizade, H. Ramamoorthy, A. Rivera, R. Russell, J. Sonntag, R. Swift, J. Yungel and J. Zwally (2004). Accelerated sea-level rise from West Antarctica, Science, 306, 255-258.

Velicogna, I., and J. Wahr (2006). Measurements of time-variable gravity show mass loss in Antarctica. Science, 311, 1754-1756.

Velicogna, I. (2009). Increasing rates of ice mass loss from the Greenland and Antarctic ice sheets revealed by GRACE. Geophys. Res. Lett., 36, L19503.

Velicogna, I., and J. Wahr (2013). Time-variable gravity observations of ice sheet mass balance: Precision and limitations of the GRACE satellite data, Geophys. Res. Lett., 40, 3055-3063; doi:10.1002/grl.50527.

Wahr, J., M. Molenaar and F. Bryan (1998). Time variability of the Earth's gravity field: Hydrological and oceanic effects and their possible detection using GRACE, J. Geophys. Res., 103, 30205-30229.

Whitehouse, P.L., M.J. Bentley and A.M. Le Brocq (2012a). A deglacial model for Antarctica: geological constraints and glaciological modelling as a basis for a new model of Antarctic glacial isostatic adjustment, Quat. Sci. Rev., 32, 1-24.

Whitehouse, P.L., M.J. Bentley, G.A. Milne, Matt A. King and Ian D. Thomas (2012b). A new glacial isostatic adjustment model for Antarctica: calibrated and tested using observations of relative sea-level change and present-day uplift rates, Geophys. J. Int., 190, 1464-1482.

Wingham, D.J., A. Shepherd, A. Muir and G.J. Marshall (2006). Mass balance of the Antarctic ice sheet, Phil. Trans. R. Soc. A., 364, 1627-1635.

Wu, X.P., M.B. Heflin, H. Schotman, B.L.A. Vermeersen, D. Dong, R.S. Gross, E.R. Ivins, A.W. Moore and S.E.
Owen (2010). Simultaneous estimation of global present-day water transport and glacial isostatic adjustment, Nat. Geosci., 3, 642-646.

Zwally, H.J., M.B. Giovinetto, J. Li, H.G. Cornejo, M.A. Beckley, A.C. Brenner, J.L. Saba and D. Yi (2005). Mass changes of the Greenland and Antarctic ice sheets and shelves and contributions to sea-level rise: 1992-2002, J. Glaciol., 51, 175, 509-527.

\footnotetext{
${ }^{\star}$ Corresponding author: Shuanggen Jin, Shanghai Astronomical Observatory, Chinese Academy of Sciences, Shanghai, China, and Bulent Ecevit University, Department of Geomatics Engineering, Zonguldak, Turkey; email: sgjin@shao.ac.cn; sg.jin@yahoo.com.

(C) 2016 by the Istituto Nazionale di Geofisica e Vulcanologia. All rights reserved.
} 